\title{
Review of Photogrammetry-Based Techniques for Characterization and Hazard Assessment of Rock Faces
}

\author{
Dwayne D. Tannant* \\ School of Engineering, University of British Columbia, Kelowna, Canada
}

\begin{abstract}
Photogrammetry-based techniques offer a fast and inexpensive way to obtain data needed for geotechnical characterization and hazard assessment of steep rock faces. These techniques also mitigate fieldwork risks associated with conventional structural mapping methods. A camera can function as an accurate survey tool, in most cases as accurate as conventional laser-based survey equipment. Millions of 3D coordinates can be determined from only a few photographs. Mounting a camera on an Unmanned Aerial Vehicle (UAV) solves many of the challenges associated with measuring and mapping steep rock faces. Small low-cost UAVs offer operational flexibility and high quality images. With good photographs taken from appropriate locations, photogrammetry or structure from motion software can generate accurate point clouds, digital surface or terrain models, and orthophotos. With further analysis and interpretation, these can yield the geotechnical data needed to create realistic models in discrete element or finite element software to perform stability assessment.
\end{abstract}

Keywords: geotechnical mapping, rock faces, photogrammetry, Structure from Motion, Digital Terrain Model, rockfall hazards

\section{Introduction}

The geological hazards associated with steep rock faces typically include rockfalls and structurally controlled instabilities such as wedge, translational, and toppling failures (Wyllie and Mah 2004). The analysis of the stability of a rock slope and the design of rock stabilization measures for steep rock slopes rely on knowledge of the rock face geometry and the rock mass conditions and orientations of joint sets as well as specific geological features such as faults. Traditionally, field measurements to obtain joint orientation data are obtained from scan-line mapping using a geological compass. However, mapping with a geological compass near steep rock slopes, such as bench faces found in open pit mines, presents numerous problems. Some examples are (i) safe access often does not exist to the rock faces to carry out geological mapping, (ii) it is difficult to measure the orientation and geometry of large geological structures such as faults by simply measuring an orientation where a scanline crosses the fault, and (iii) mapping with a compass at the base of a steep slope exposes people to harm from rockfalls.

The solution is to measure and map features of interest from a safe distance. Three techniques that can be used are photogrammetry using stereo-pairs of photographs, 'Structure from Motion' using many overlapping photographs acquired from different camera positions, and lidar (laser scanning). Given the low cost for digital cameras compared to laser scanners and their ease of use in the field, the techniques using photogrammetric image processing are

*Corresponding Author: Dwayne Tannant, dwayne.tannant@ubc.ca, +1 250.807.8067 
particularly useful for geotechnical characterization of rock slopes (Birch 2006, Haneberg 2008, Tannant et al 2008, Sturzenegger and Stead 2009, Bahrani and Tannant 2011, Kim et al 2013, Vasuki et al 2014). This paper reviews the use of photographs as a powerful measuring and mapping tool for steep rock slopes. It also discusses the use of small Unmanned Aerial Vehicles (UAV) as a platform to take photographs from optimal positions above the ground. The paper outlines best practices for obtaining photographs for photogrammetry purposes and limitations in an open pit mining environment.

\section{Photogrammetry, Structure from Motion, and Multi-View Stereo}

Photogrammetry has been widely used for more than a century for mapping purposes (Wolf et al 2014). Photogrammetry is a measurement technique that uses light rays captured by a camera. The technique fundamentally requires two photographs of the same object taken from different locations. Modern digital photogrammetry and image processing can be accomplished with commercial software that has been designed for geotechnical mapping purposes (e.g. 3DM Analyst and Sirovision). Generally, the software uses a stereopair of photos and automatically identifies and uses multiple corresponding points in each photograph to determine the camera location and orientation, and the 3D coordinates of common points in the photos by a complex bundle adjustment algorithm.

Structure from Motion or SfM is an image processing technique that was originally developed for computer vision applications (Civera et al 2012). Some fundamental mathematics used in SfM techniques, including camera pose estimation, camera calibration, triangulation, and bundle adjustment (block adjustment), were adapted from photogrammetry. Using multiple overlapping images, the SfM algorithms can estimate the camera pose parameters and generate sparse point-clouds. Further image processing using Multiple View Stereo (MVS) can generate a dense point cloud once the correspondence among multiple camera locations has been established.
SfM-MVS using many photos (10s to 100 s) will typically produce denser point clouds (more $3 \mathrm{D}$ coordinates) than photogrammetry processing of a stereo-image pair. Recent software developments have improved the processing speed, increased the density of the resulting point clouds, and improved the accuracy of the generated 3D data, while better eliminating outliers. Image processing using SfM and MVS has been implemented in commercial software (e.g., Inpho, Pix4D, PhotoModeler, and Photoscan), web-based services (e.g., Arc3D, Autodesk 123D, and Photosynth) and in opensource software (Pierrot-Deseilligny and Clery 2011, Remondino et al 2012, Rothemel et al 2012, Bartoš et al 2014, Remondino et al 2014).

Many early publications concerning photogrammetry applications in geotechnical engineering were concerned with its accuracy compared to traditional methods such as the use of a geological compass for measuring the orientation of joints or the use of a total station for measuring profiles of rock faces (Martin et al 2007, Sturzenegger and Stead 2009, Küng et al 2011, Harwin and Lucieer 2012, Fonstad et al 2013). Through these comparisons, the photogrammetry techniques have now been proven effective and accurate, and thus recent publications simply present photogrammetrybased rock characterization as an accepted site investigation tool. The accuracy of the resulting $3 \mathrm{D}$ coordinates of features on the ground is controlled by the choice of the camera/lens, object distance, and the spacing between camera locations. Coordinate accuracy in the order of a few centimetres is possible with typical workflows for investigation of geohazards originating from cliff faces. It is important to note that the accuracy is not a function of the photogrammetry software; the software can easily yield sub-millimetre accuracy using close range photos of small objects. The accuracy needed for the site investigation and the size of the rock face is used to select an appropriate combination of lens focal length, objective distance, and camera spacing. From a practical perspective, it is often helpful to avoid collection of too many photos resulting from use of long focal lengths or short object distances because the resulting data set and 
models can quickly become very large and difficult to process and store.

\section{Measurement and Mapping}

Recent advances in photogrammetric image processing software now allow for surveying and mapping of steep rock slopes in a much faster and safer manner compared to traditional geotechnical mapping practices. Hundreds of thousands to millions of coordinates can be measured from only a few photographs. A good camera can function as an accurate survey tool, with accuracy comparable to laser-based survey equipment (Martin et al 2007, Küng et al 2011, Harwin and Lucieer 2012, Fonstad et al 2013).

The output from digital photogrammetry or SfM/MVS image processing is a point cloud consisting of a large number of 3D coordinates, each with its own color attribute. These coordinates can be used to generate a triangular irregular network over which the textural information from the images is draped to create Digital Surface Model (DSM) or Digital Terrain
Model (DTM). These models can provide a basis for subsequent interpretation, measurement, and mapping.

To illustrate how little field information and effort are needed to generate a useful model with abundant geometric information, two photos were taken of a small rock cut along a road that had experienced a wedge failure. The camera used was a Canon 5D Mark II with a $24 \mathrm{~mm}$ fixed focal length lens. The fieldwork required for this example was only to take the photos (less than a few minutes of work). No tripod or ground control points were used and no additional surveying was conducted other than to note the presence of a vertical fence post and the size of some rockbolt plates captured in the photos. 3DM Analyst software (version 2.5.0, Adam Technology 2013) was used to create a 3D model with more than 600,000 coordinates and to perform the joint mapping. Figure 1 shows the model.

The fence post was used to ensure that the

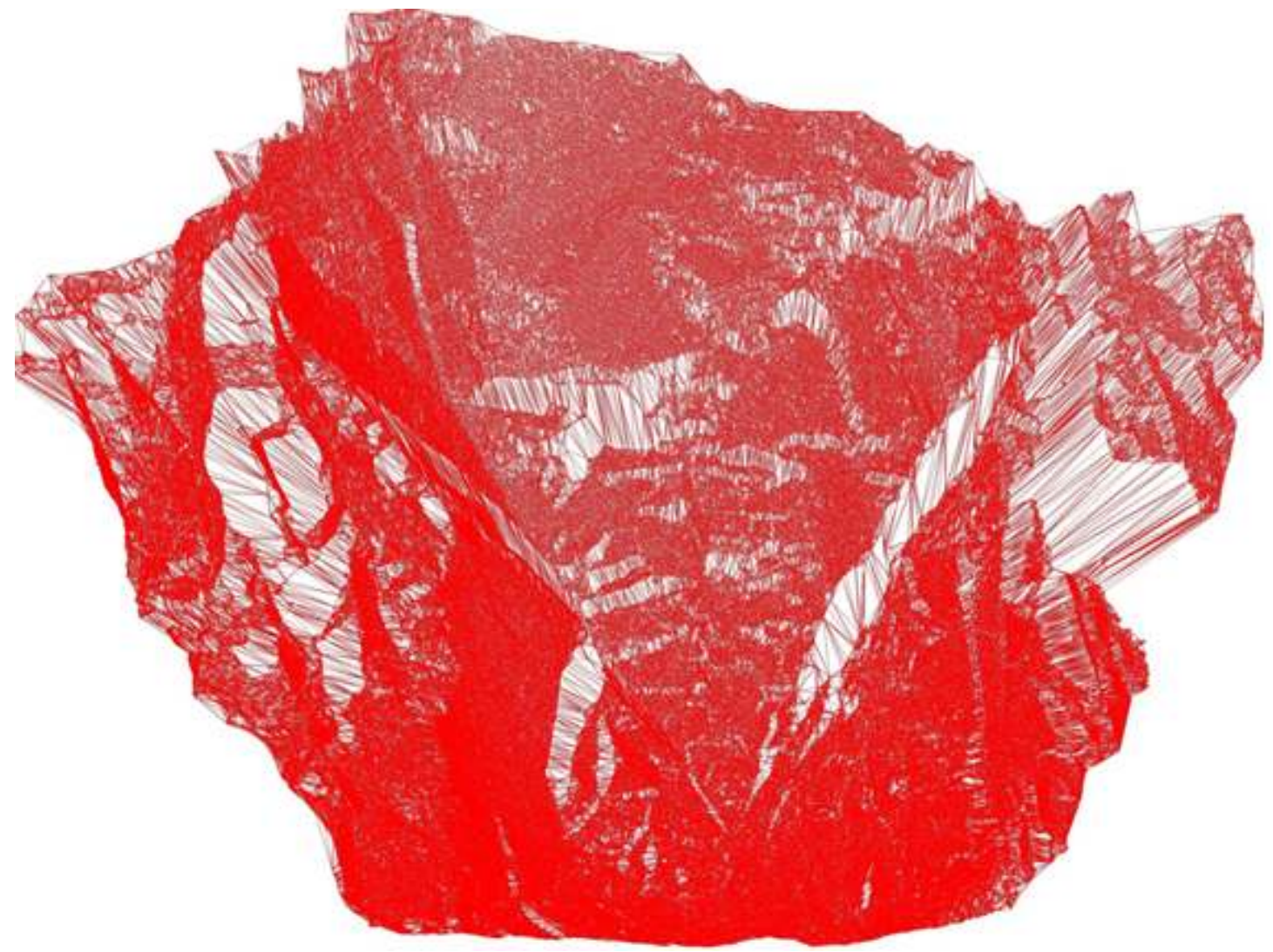

Figure 1. Point cloud with 607,487 points from a small section of a rock slope used to create a TIN with 1,214,945 triangles covering $524 \mathrm{~m}^{2}$ 
model was oriented correctly in the vertical direction and the rockbolt plates were used to provide scale to the model (albeit with some error given the small size of the plates relative to the overall model dimensions). A more accurate scaling of the model could have been obtained by measuring the distance between two rockbolts, for example.

When processing the photos in the photogrammetry software, the camera locations relative to the rock cut are obtained. The distance between the two camera locations was determined to be $5.35 \mathrm{~m}$ and the distance from the cameras to the middle of the wedge area was approximately 15 to $25 \mathrm{~m}$. Using these dimensions and the camera/lens characteristics, the theoretical coordinate accuracy in the model was approximately $20 \mathrm{~mm}$. This is more than adequate to characterize many geometric features of relevance to the wedge failure, which had a height and width of roughly $15 \mathrm{~m}$. The model with contour lines added is shown in Figure 2 and further mapping and analysis results are presented in Figure 3 and Figure 4 to give some indication of how a typical model can be used.

Often it is useful to have the resulting point cloud data or DSM/DTM created in a known coordinate system. This can be accomplished by direct and indirect geo-referencing. Direct georeferencing can take advantage of a GPS receiver associated the camera. The camera location when an image is taken can be recorded in the image Exif data as geographical coordinates in the WGS84 format. Some processing software (e.g., Pix4D) can directly access and use the camera coordinates to geo-reference the generated point cloud or digital model.

Indirect geo-referencing is done using ground control targets that are captured in the images. Typically, targets (ground control points) are placed on or near a rock face to geo-reference and scale the resulting 3D model. These ground control points are independently surveyed using, for example, a differential GPS or total station.

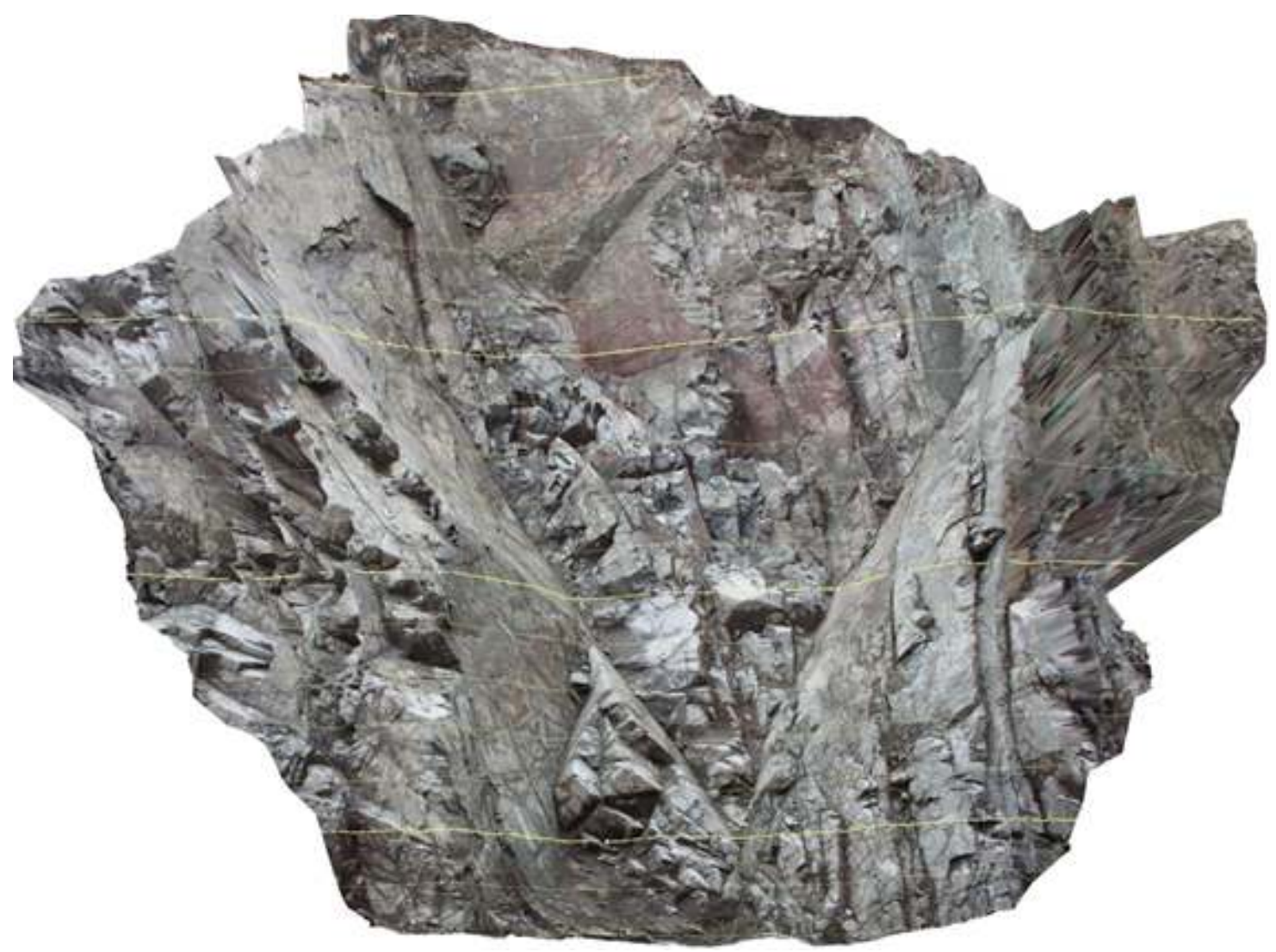

Figure 2. Oblique view of a digital terrain model of a small section of a rock slope excavated in a blocky rock mass with $1 \mathrm{~m}$ contour lines shown in yellow 


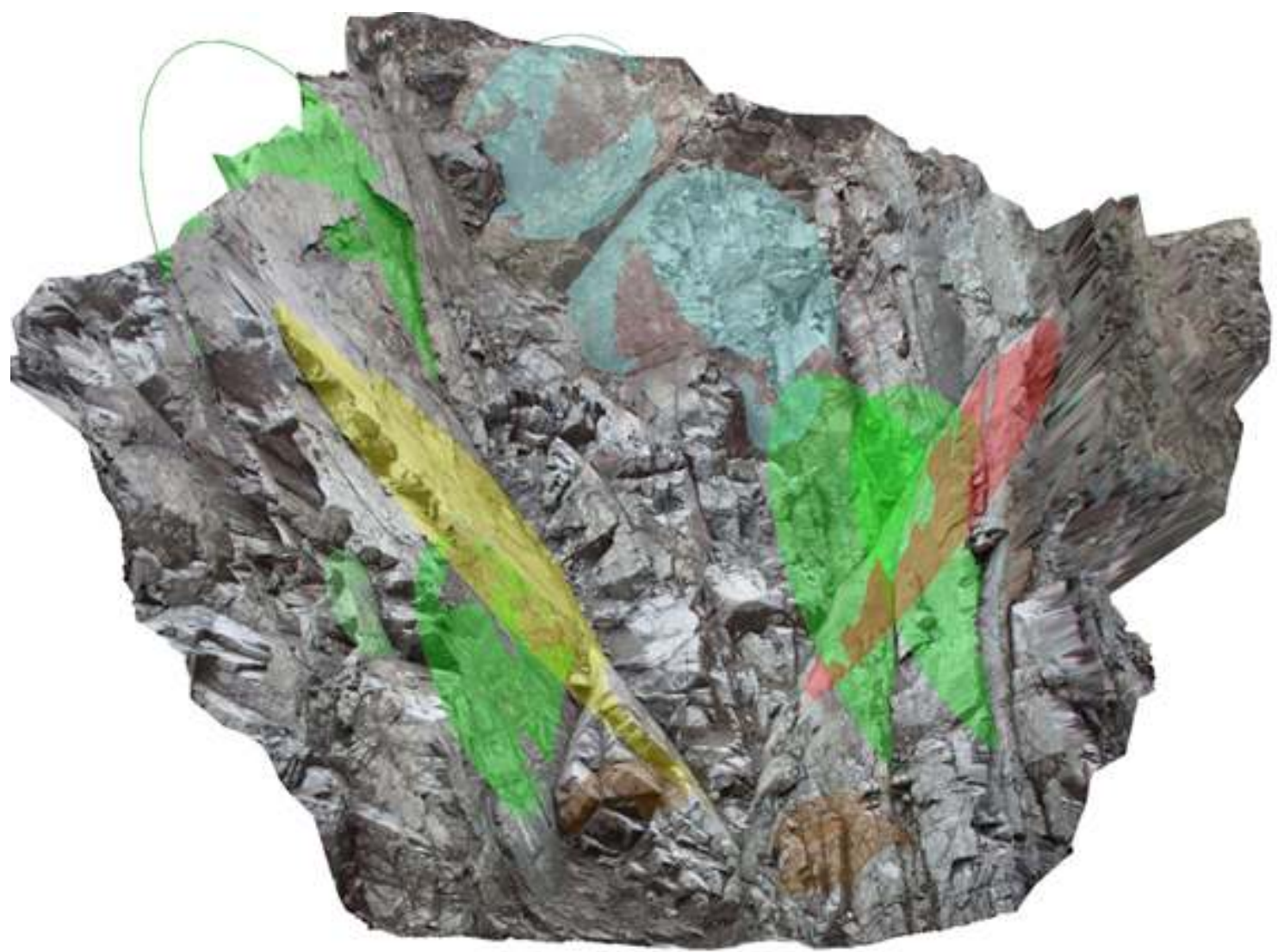

Figure 3. Joints mapped in a digital terrain model (yellow and red joints formed the base of a wedge failure)

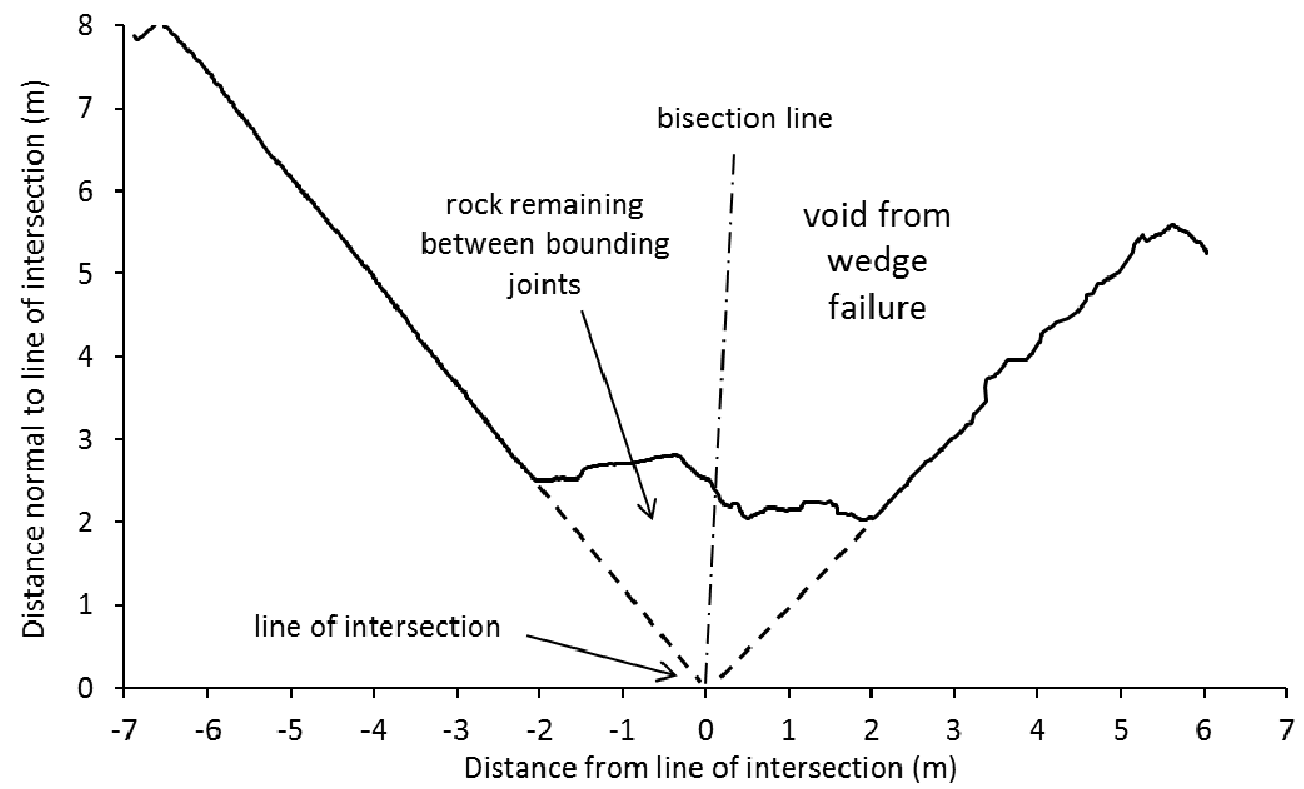

Figure 4. Rock surface profile taken perpendicular to the line of intersection of the yellow and red joints mapped in Figure 3 showing the true wedge angle and rock that remains between the bounding joints 
The ground control coordinates are used during image processing in the software to geo-reference the generated point cloud or digital model.

For rock faces, the 3D digital terrain or digital surface models generated from the photographs can be used for various geotechnical measurement and mapping purposes (Tannant et al 2006). For example, Figure 3 shows some joints mapped in a digital terrain model and Figure 4 shows a wedge cross-section profile obtained from the digital terrain model. Other examples can be found in Birch (2006), Tannant and Anonby (2007), Haneberg (2008), Tannant et al (2008), Sturzenegger and Stead (2009), Tannant (2010), Bahrani and Tannant (2011), Kim et al (2013), Ružić et al (2014) and Vasuki et al (2014), and these include the following measurement and mapping purposes:

- map faults and other structures and trace them between benches with high location and orientation accuracy,

- determine the coordinates and dip and dip direction of joints,

- record structural/geotechnical parameters such as waviness, spacing, trace length, etc.,

- measure as-built wall angles and bench widths, length of pre-split half barrels, etc.,

- create contour maps and cross-sections,

- measure burden on bench faces for optimizing blast designs and minimizing flyrock,

- calculate volumes, and

- detect changes caused by erosion or slope movement using photos acquired at different times.

Photogrammetric image processing has also been used in other geoscience applications such as geomorphic studies (Stefanik et al 2011, Westoby et al 2012, Hugenholtz et al 2013, Whitehead et al 2014), hazard assessments (Lin et al 2010, Yang et al 2012), landslides (Lucieer et al 2014, Marek et al 2015, Stumpf et al 2015, Torrero et al 2015), and rockfalls (Di Crescenzo and Santo 2007, Salvini et al 2013, Giordan et al 2015a).

\section{Advantages}

Photogrammetry and structure from motion techniques have many advantages compared to conventional mapping with geological compasses or surveying with lidar instruments. The fieldwork is quick and cost effective leaving more time for interpretation and digital mapping. Hazardous slope locations can be measured and mapped from a safe location. The fieldwork usually has minimal impact on mining activities compared to manual methods. The photographs provide a permanent archival record of the rock face condition and excavation stages. The digital models generated from the photographs can be very detailed and precise and they can be analyzed to map and measure structural orientation data. The models provide a realistic representation of discontinuity orientations and lengths. Often it is possible to detect geological and structural trends that are not obvious when close to the face. Orthorectified photomosaics can be created from the acquired images.

A camera is less expensive, easier, and faster to use than a lidar instrument. Any camera can be used to acquire the images although the detail and accuracy of the resulting data depend on the quality of the camera and lenses used.

The geometry and geological structures identified in the DSM/DTM can be used as input to discrete fracture network, discrete element, and finite element models for further stability analyses (Firpo et al 2011, Shamekhi and Tannant 2011, Booth and Meyer 2013, Ortega et al 2013, Francioni et al 2014, Bonilla-Sierra et al 2015, Kim et al 2015, Lai et al 2015).

\section{Limitations}

As with any measuring technique, there are limitations that should be considered when planning the fieldwork and the subsequent image processing. Photogrammetry and structure from motion techniques work best when there is a certain separation or base distance between each camera location that is proportional to the distance between the camera and the rock face. This restricts the locations on the ground best suited for taking the photographs. When taking photos of rock faces from ground locations, it is often difficult to find suitable camera locations that have an appropriate base distance and that are oriented along a line that is parallel to the rock face. 
The presence of vegetation can obscure part of the rock face. Vegetation can present a problem where (1) it restricts visibility of a rock face near the camera locations and (2) where vegetation exists on the rock slope itself. A lidar survey only requires a single instrument location while a photogrammetry survey needs at least two locations. Therefore, when working where vegetation is present, there is 'twice' as much opportunity for vegetation to be in the way when taking photos. Lidar has an advantage on vegetated slopes because it can record multiple reflections and a bare-earth model can be obtained by filtering out coordinates corresponding to the vegetation. The Structure from Motion technique can almost replicate the data acquired by lidar because when many different camera locations are used, SfM/MVS image processing increases the possibility to 'see' through the vegetation and measure coordinates on the rock surface.

The image matching algorithms may not work well if the images are taken at significantly different times/dates resulting in a different appearance for the same features on the rock face. For example, lighting conditions and shadows on a rock face will change over time. If the rock surface is partially covered with snow or is wet, its appearance can change over time during melting and drying. While typically not an issue, if the rock face has a uniform texture with little colour contrast, the image matching algorithms in the software may not work well.

Typically, the most time consuming and difficult aspect of the fieldwork is establishing and surveying ground control points that are used to scale, orient, and georeference the resulting models. Ideally, these points are installed on the rock face itself, which can expose people to rockfall risks. This limitation can be minimized for ground-based photographs by accurately measuring the camera location for each photograph.

If portions of the rock face cannot be seen from multiple camera locations, they cannot be measured - only what can be seen can be measured. For example, when taking photos of a rock face from the ground, the available camera locations are usually at or below the elevation of the base of the rock face. This means that all the photos are taken with the camera pointed upward. Thus, the camera orientation is typically oblique to the rock face rather than in a more ideal orientation, which is perpendicular to the rock face. In addition, if the rock face has near horizontal steps or benches, the tops of these structures may be occluded and cannot be seen in the photographs.

Construction of 3D digital models for subsequent geotechnical analysis is typically limited to photographs taken from distances closer than roughly $2 \mathrm{~km}$ from the rock slope. For more detailed discontinuity evaluation, the distance should probably not exceed 500 to 1000 $\mathrm{m}$. For smaller scale rock cuts (e.g. bench height in an open pit), a typical object distance is in the range of 10 to $100 \mathrm{~m}$, which typically yields very good quality models.

Using photographs to build models of rock slopes has limited ability to evaluate discontinuity properties such as infilling, shape, small-scale roughness, joint wall strength, etc. These discontinuity properties are best evaluated by direct observation in the field. However, fundamentally many of these parameters can be assessed if very close range photogrammetry is used.

Many of the limitations discussed here are associated with constraints imposed on the location of the camera when taking photos from the ground. A solution is to take the photos from locations above the ground and with the recent developments in UAV technologies, these limitations disappear (see Section 7).

\section{Best Practices in the Field}

The main factors controlling the accuracy of the data include:

- focal length of the camera lens,

- distance of the camera from the rock face, and

- separation or base distance between camera locations relative to the object distance.

The user can choose the lens and ratio to fit the accuracy requirements of the job.

The focal length and distance from the rock face determine the size of the area covered by each pixel in the image. Small base distances lead to poor numerical solutions for the camera 
location and orientation parameters, whereas large baselines introduce problems in feature matching.

Accuracy of the surveyed ground control points can also influence the georeferencing, scale, and orientation of the resulting DSM/DTM.

There are fieldwork and photography techniques that can increase the success of using photographs to construct accurate DSM/DTMs. It is best to use a fixed focal length lens to ensure the best possible camera calibration. Better quality cameras and lens yield better photographs. If a camera with a zoom lens is used, do not change the zoom setting while taking the photographs. Ideally, photos taken from the ground should be shot using a tripod.

In terms of camera settings, shoot the under aperture priority with the aperture set to approximately $f 8.0$ when using DSLR cameras shot from the ground. If shooting the photos from a UAV, open the aperture to permit faster shutter speeds. Images should be recorded in the camera's native raw format if available.

In terms of camera position and orientation, take photographs from camera locations that are roughly parallel to the rock face and take photographs with the lens oriented approximately perpendicular to the rock face.

Consider the orientation of the rock face when determining the best time of the day to take photographs to avoid dark shadows. If dealing with vegetation, photos taken in the early spring can minimize the presence of leaves. Take photos in quick succession to avoid changes in shadows and drying of rock.

\section{Unmanned Aerial Vehicles}

The use of UAVs or drones as a data acquisition platform is quickly becoming a very useful tool for many surveying and mapping applications in mining and other geoscience areas (Stefanik et al 2011, Nex and Remondino 2013, Lucieer et al 2014, Shahbazi al 2014, Vasuki et al 2014, Whitehead and Hugenholtz 2014, Giordan et al 2015a,b, Marek et al 2015, Torrero et al 2015). The enabling technologies include highly accurate Global Positioning Systems, costefficient and light gyroscopes and inertial motion units to measure alignment and orientation, and robust micro-processors and software to allow for flight control and autonomous navigation.

Many of the limitations when using a camera to take images from ground locations can be eliminated by mounting a camera to a UAV. A UAV can fly close to the rock face to capture detailed images. Many competing companies in this sector are driving down the costs and increasing the functionality of the UAV systems (e.g., 3D Robotics, DJI, SenseFly, and Trimble).

UAVs used in mining applications are evolving towards smaller and less expensive platforms that can be deployed rapidly in the field. They fall into two categories: (i) multi-rotor vertical takeoff and landing UAVs and (ii) fixed wing UAVs. The small UAVs used for the mining industry typically run on rechargeable lithium-ion polymer batteries. Depending on the size of the drone, they can last from 20 minutes (multi-rotor) to an hour or more (fixed wing) in the air.

Because of their longer flight times and inability to hold a fixed position, fixed wing UAVs tend to be used where a larger area of coverage is desired. Fixed wing UAVs are often best used in situations where a vertical downward orientation (nadir imaging) of the camera is desired. When taking images of very steep rock faces, the appropriate camera orientation is often nearly horizontal and this configuration works well for multi-rotor UAVs. The flexibility of a multi-rotor UAV can allow up-and-down or backand-forth flight paths. Thus for taking photographs of steep to near vertical rock faces, a multi-rotor UAV is usually the best choice.

The current small UAVs have navigational functions like position hold (multi-rotor only), return-to-home, and flight planning defined by pre-programmed waypoints. The flight path is typically defined using GPS waypoints that are stored in a digital file and submitted wirelessly to the UAV from a ground control station, a mobile computer, or smartphone.

A UAV may be launched manually or automatically into air and it will typically fly the selected flight path autonomously. While flying, an operator will monitor the UAV from the ground. The operator can override the autonomous flight control and take over manual 
control if needed. For safety and security reasons, UAV use is typically restricted to flights within line-of-sight of an operator (Rango and Laliberte 2010).

The use of a UAV is usually more convenient in areas with frequent cloud cover that complicates the planning of manned aerial photography missions. A UAV can be deployed quickly when a break in the clouds occurs whereas a manned aircraft takes much longer to organize.

While a typical UAV is equipped with a simple digital camera, multispectral sensors and light-weight lidar sensors can also be used, thus expanding the range of data that can be acquired with a UAV.

The potential for UAV technology in surveying, mapping, and geohazard evaluation is enormous. Their use will become common because they provide a huge advantage of having cost-effective 'eyes in the sky'.

\section{Conclusions}

A camera combined with photogrammetry software can function as an accurate survey tool, in most cases as accurate as conventional laserbased survey equipment. Using photographs as the prime measurement tool offers safety, speed, and rich archival-quality data sets for geotechnical investigations.

Millions of coordinates can be measured from only a few photographs. By mounting a camera on a UAV, many of the challenges associated with measuring and mapping steep rock faces can be easily solved. The current generation of small low cost UAVs offers operational flexibility and high quality images.

The use of photogrammetry or Structure from Motion techniques can be an effective surveying and mapping tool in open pit mines and steep rock slopes. These techniques also mitigate risks associated with conventional structural mapping for geotechnical purposes.

\section{Acknowledgements}

This work was supported by the Natural Sciences and Engineering Research Council of Canada. Assistance in the field from numerous graduate students over the past decade is also acknowledged.

\section{References}

3DM Analyst, http://www.adamtech.com.au

3D Robotics, http://3drobotics.com/

Arc3D, http://www.arc3d.be

Autodesk 123D, http://www.123dapp.com

Bahrani, N. and D.D. Tannant, 2011. Field-scale assessment of effective dilation angle and peak shear displacement for a footwall slab failure surface. Int. J. of Rock Mech. \& Mining Sci., 48(4): 565 - 579. DOI: 10.1016/ j.ijrmms.2011.02.009

Bartoš, K., K. Pukanská and J. Sabová, 2014. Overview of available open-source photogrammetric software, its use and analysis. Int. J. for Innovation Education and Research, 2(4): 62 - 70.

Birch, J.S., 2006. Using 3DM Analyst mine mapping suite for rock face characterization. In: Tonon, F. and J. Kottenstette (eds.): Laser and Photogrammetric Methods for Rock Face Characterization. Proc. $41^{\text {st }}$ U.S. Rock Mechanics Symp., Golden, USA.

Bonilla-Sierra, V., L. Scholtès, F.V. Donzé and M.K. Elmouttie, 2015. Rock slope stability analysis using photogrammetric data and DFN-DEM modelling. Acta Geotechnica, pp DOI: $10.1007 / \mathrm{s} 11440-015-0374-\mathrm{Z}$

Booth, P.W. and G.E. Meyer, 2013. Quarry wall stability and design optimisation using photogrammetric mapping and analysis techniques. Proc. Slope Stability 2013, Perth, Australia.

Civera, J., A.J. Davison and J.M. Martínez Montiel, 2012. Structure from Motion Using the Extended Kalman Filter. Springer. DOI: 10.1007/978-3-642-24834-4

Di Crescenzo, G. and A. Santo, 2007. Highresolution mapping of rock fall instability through the integration of photogrammetric, geomorphological and engineering-geological surveys. Quaternary Int., 171-172: 118 - 130. DOI: $10.1016 /$ j.quaint.2007.03.025

DJI, http://www.dji.com

Firpo, G., R. Salvini, M. Francioni and P.G. Ranjith, 2011. Use of digital terrestrial photogrammetry in rocky slope stability 
analysis by distinct elements numerical methods. Int. J. of Rock Mech. and Mining Sci., 48(7): 1045 - 1054. DOI: 10.1016/j.ijrmms.2011.07.007

Fonstad, M.A., J.T. Dietrich, B.C. Courville, J.L. Jensen and P.E. Carbonneau, 2013. Topographic structure from motion: a new development in photogrammetric measurement. Earth Surface Processes and Landforms, $38(4)$ : 421 - 430. DOI: 10.1002/esp.3366

Francioni, M., R. Salvini, D. Stead and S. Litrico, 2014. A case study integrating remote sensing and distinct element analysis to quarry slope stability assessment in the Monte Altissimo area, Italy. Eng. Geology, 183: 290 - 302. DOI: 10.1016/j.enggeo.2014.09.003

Giordan, D., A. Manconi, A. Facello, M. Baldo, F. dell'Anese, P. Allasia and F. Dutto, 2015a. Brief Communication: the use of an unmanned aerial vehicle in a rockfall emergency scenario. Nat. Hazards Earth Syst. Sci., 15: 163 - 169. DOI: 10.5194/nhess-15-163-2015

Giordan, D., A. Manconi, D.D. Tannant and P. Allasia, 2015b. UAV: low-cost remote sensing for high-resolution investigation of landslides. IEEE Geoscience and Remote Sensing Society, International Geoscience and Remote Sensing Symp., Milan, Italy.

Haneberg W.C., 2008. Using close range terrestrial digital photogrammetry for 3-D rock slope modeling and discontinuity mapping in the United States. Bull. Eng. Geol. Environ., 67(4): 457 - 469. DOI: 10.1007/s10064-008$0157-y$

Harwin, S. and A. Lucieer, 2012. Assessing the accuracy of georeferenced point clouds produced via multi-view stereopsis from unmanned aerial vehicle (UAV) imagery. Remote Sens., 4(6): 1573 - 1599. DOI: $10.3390 /$ rs 4061573

Hugenholtz, C.H., K. Whitehead, O.W. Brown, T.E. Barchyn, B.J. Moorman, A. LeClair, K. Riddell and T. Hamilton, 2013. Geomorphological mapping with a small Unmanned Aircraft System (sUAS): feature detection and accuracy assessment of a photogrammetrically-derived digital terrain model. Geomorphology, 194: 16 - 24. DOI: 10.1016/j.geomorph.2013.03.023

Inpho, http://www.trimble.com/Imaging/Inpho.aspx

Kim, D.H., I. Gratchev and A. Balasubramaniam, 2013. Determination of Joint Roughness Coefficient (JRC) for slope stability analysis: a case study from the Gold Coast area, Australia. Landslides, 10(5): 657 - 664. DOI: 10.1007/s10346-013-0410-8

Kim, D.H., I. Gratchev and A. Balasubramaniam, 2015. Back analysis of a natural jointed rock slope based on the photogrammetry method. Landslides, 12(1): 147 - 154. DOI: 10.1007/s10346-014-0528-3

Küng, O., C. Strecha, A. Beyeler, J.C. Zufferey, D. Floreano, P. Fua and F. Gervaix, 2011. The accuracy of automatic photogrammetric techniques on ultra-light UAV imagery. Proc. Int. Conf. on Unmanned Aerial Vehicle in Geomatics (UAV-g), Zurich, Switzerland.

Lai, X.P., P.F. Shan, M.F. Cai, F.H. Ren and W.H. Tan, 2015. Comprehensive evaluation of highsteep slope stability and optimal high-steep slope design by 3D physical modeling. Int. J. of Minerals, Metallurgy and Materials, 22(1). DOI: $10.1007 / \mathrm{s} 12613-015-1036-8$

Lin, J., H. Tao, Y. Wang and Z. Huang, 2010. Practical application of unmanned aerial vehicles for mountain hazards survey. Proc. IEEE $18^{\text {th }}$ Geoinformatics Int. Conf., Beijing, China.

Lucieer, A., S.M. de Jong and D. Turner, 2014. Mapping landslide displacements using Structure from Motion (SfM) and image correlation of multi-temporal UAV photography. Progress in Physical Geography, 38(1): 97 - 116. DOI: $10.1177 /$ 0309133313515293

Marek, L., J. Miřrijovský and P. Tuček, 2015. Monitoring of the shallow landslide using UAV photogrammetry and geodetic measurements. Proc. Engineering Geology for Society and Territory 2, IAEG, Torino, Italy.

Martin, C.D., D.D. Tannant and H. Lan, 2007. Comparison of terrestrial-based, high resolution, LiDAR and digital photogrammetry surveys of a rock slope. Proc. $1^{\text {st }}$ 
Canada-US Rock Mechanics Symp., Vancouver, Canada.

Nex, F. and F. Remondino, 2013. UAV for 3D mapping applications: a review. Applied Geomatics, 6(1): 1 - 15. DOI: 10.1007/s12518013-0120-x

Ortega, I., P.W. Booth and J. Darras, 2013. Stability analysis and remedial design of two road cuttings in North Queensland based on remote geotechnical mapping using digital photogrammetry. Proc. Slope Stability, 2013, Perth, Australia.

PhotoModeler, http://www.photomodeler.com

Photoscan, http://www.agisoft.com

Photosynth, https://photosynth.net

Pierrot-Deseilligny, M. and I. Clery, 2011. APERO, an open source bundle adjustment software for automatic calibration and orientation of set of images. ISPRS Trento 2011 Workshop. Int. Archives of Photogrammetry, Remote Sensing and Spatial Information Sciences, 38: 269 - 276.

Pix4D, https://pix4d.com

Rango, A. and A.S. Laliberte, 2010. Impact of flight regulations on effective use of unmanned aircraft systems for natural resources applications. J. Appl. Remote Sens., 4(1): 043539. DOI: $10.1117 / 1.3474649$

Remondino, F., S. Del Pizzo, T. Kersten and S. Troisi, 2012. Low-cost and open-source solutions for automated image orientation $-\mathrm{a}$ critical overview. Progress in Cultural Heritage Preservation, 7616: 40 - 54. DOI: 10.1007/978-3-642-34234-9 5

Remondino, F., M.G. Spera, E. Nocerino, F. Menna and F. Nex, 2014. State of the art in high density image matching. The Photogrammetric Record, 29(146): 144-166. DOI: 10.1111/phor. 12063

Rothermel, M., K. Wenzel, D. Fritsch, N. Haala, 2012. SURE: Photogrammetric surface reconstruction from imagery. Proc. LC3D Workshop, Berlin, Germany.

Ružić, I., I. Marović, Č. Benac and S. Ilić, 2014. Coastal cliff geometry derived from structurefrom-motion photogrammetry at Stara Baška, Krk Island, Croatia. Geo-Marine Letters, 34(6): 555 - 565. DOI: 10.1007/s00367-014-0380-4
Salvini R., M. Francioni, S. Riccucci, F. Bonciani and I. Callegari, 2013. Photogrammetry and laser scanning for analyzing slope stability and rock fall runout along the Domodossola-Iselle railway, the Italian Alps. Geomorphology, 185: 110 - 122. DOI: 10.1016/j.geomorph.2012. 12.020

SenseFly, https://www.sensefly.com/home.html Shahbazi, M., J. Théau and P. Ménard, 2014. Recent applications of unmanned aerial imagery in natural resource management. GIScience \& Remote Sensing, 51(4): 339 365. DOI: $10.1080 / 15481603.2014 .926650$

Shamekhi, E. and D.D. Tannant, 2011. Cedar Pit highwall and fault monitoring with photogrammetry at Elkview Mine. Proc. Int. Symp. on Rock Slope Stability in Open Pit Mining and Civil Engineering, Vancouver, Canada.

Sirovision, http://sirovision.com/

Stefanik, K.V., J.C. Gassaway, K. Kochersberger and A.L. Abbott, 2011. UAV-based stereo vision for rapid aerial terrain mapping. GIScience \& Remote Sensing, 48(1): 24 - 49. DOI: $10.2747 / 1548$ - 1603.48.1.24

Stumpf, A., J.P. Malet, P. Allemand, M. PierrotDeseilligny and G. Skupinski, 2015. Groundbased multi-view photogrammetry for the monitoring of landslide deformation and erosion. Geomorphology, 231: 130 - 145. DOI: 10.1016/j.geomorph.2014.10.039

Sturzenegger, M. and D. Stead, 2009. Closerange terrestrial digital photogrammetry and terrestrial laser scanning for discontinuity characterization on rock cuts. Engineering Geology, 106(3-4): 163 - 182. DOI: 10.1016/j.enggeo.2009.03.004

Tannant, D.D., J. Radmanovic J. and L. Jiang, 2006. Digital photogrammetry for surface mining applications. Proc. CIM Mining Conference and Exhibition, Vancouver, Canada.

Tannant, D.D. and D. Anonby, 2007. Blast modifications to improve bench width reliability at the Ekati Fox Pit. Blasting and Fragmentation, 1(1): 23 - 49.

Tannant, D.D., N. Bahrani and V. Gulati, 2008. Bedding surface roughness profiles and 
estimated dilation angles. Proc. $61^{\text {st }}$ Canadian Geotechnical Conf., Edmonton, Canada.

Tannant, D.D., 2010. Roof profiles and geological structures in Myra Canyon tunnels mapped from high resolution digital rock surface models. Proc. Int. Tunnelling Association and Underground Space Association $36^{\text {th }}$ World Tunnel Congress, Vancouver, Canada.

Torrero, L., L. Seoli, A. Molino, D. Giordan, A. Manconi, P. Allasia and M. Baldo, 2015. The use of micro-UAV to monitor active landslide scenarios. Proc. Engineering Geology for Society and Territory 5, IAEG, Torino, Italy.

Trimble, http://uas.trimble.com/trimble-uas

Vasuki, Y., E.J. Holden, P., Kovesi and S. Micklethwaite, 2014. Semi-automatic mapping of geological structures using UAV-based photogrammetric data: An image analysis approach. Computers \& Geosciences, 69: 22 32. DOI: $10.1016 /$ j.cageo.2014.04.012

Westoby, M.J., J. Brasington, N.F. Glasser, M.J. Hambrey and J.M. Reynolds, 2012. Structurefrom-Motion photogrammetry: a low-cost, effective tool for geoscience applications. Geomorphology, 179: 300 - 314. DOI: 10.1016/j.geomorph.2012.08.021
Whitehead, K. and C.H. Hugenholtz, 2014. Remote sensing of the environment with small unmanned aircraft systems (UASs), part 1: a review of progress and challenges. J. of Unmanned Vehicle Systems, 2(3): 69 - 85. DOI: $10.1139 /$ juvs-2014-0006

Whitehead, K., C.H. Hugenholtz, S. Myshak, O. Brown, A. LeClair, A. Tamminga, T.E. Barchyn, B. Moorman and B. Eaton, 2014. Remote sensing of the environment with small unmanned aircraft systems (UASs), part 2: scientific and commercial applications. J. of Unmanned Vehicle Systems, 2(3): 86 - 102. DOI: 10.1139/juvs-2014-0007

Wolf, P.A., B.A. Dewitt and B.E.Wilkinson, 2014. Elements of Photogrammetry with Applications in GIS, $4^{\text {th }}$ ed. McGraw-Hill Education.

Wyllie, D.C. and C.W. Mah, 2004. Rock Slope Engineering, $4^{\text {th }}$ ed. Spon Press.

Yang, Q., S. Chen, P. Lu, T. Cui, M. Ma, Y. Liu, C. Zhou and L. Zhao, 2012. Application of low-altitude remote sensing image by unmanned airship in geological hazards investigation. Proc. Image and Signal Processing $5^{\text {th }}$ Int. Cong., Chongqing, China. 